Proceedings of the Institution of
Civil Engineers
Geotechnical Engineering I58
January 2005 Issue GEI
Pages 3-14
Paper 13342
Received $17 / 04 / 2003$
Accepted 16/04/2004
Keywords:
piles \& piling/field testing \&
monitoring
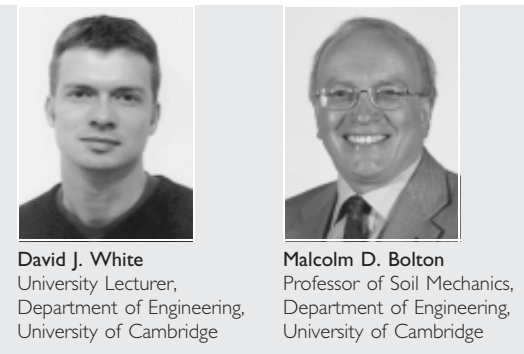

\title{
Comparing CPT and pile base resistance in sand
}

\author{
D. J. White and M. D. Bolton
}

The comprehensive database of load tests on closedended piles in sand has been re-examined to study the relationship between CPT resistance, $q_{c}$, and ultimate base capacity, $q_{b}$. The aim is to establish the origin of low reported values of $q_{b} / q_{c}$ which contrast with continuum models that suggest $q_{b}=q_{c}$ for steady deep penetration. Partial embedment of the pile tip into a hard layer underlying weak material has been accounted for by weighting $q_{\mathrm{c}}$. Partial mobilisation has been accounted for by defining failure according to a plunging criterion. When these two mechanisms are considered, the resulting values of $q_{b} / q_{c}$ have a mean value of $\mathbf{0 . 9 0}$ and show no trend with pile diameter. The remaining slight underprediction of the 'continuum' model $\left(q_{b}=q_{c}\right)$ could be attributed to the underestimation of plunging load in pile tests for which steady penetration is not reached. This exercise makes two contributions: first, it is suggested that any reduction of $q_{c}$ when estimating the end bearing capacity of closed-ended piles in sand should be linked to partial embedment and partial mobilisation, rather than absolute diameter; second, the dearth of high-quality pile load test data in the public domain is highlighted.

\section{NOTATION}

$B$

$D$

$N$

$N_{\gamma} \quad$ shallow bearing capacity factor

$\boldsymbol{Q}_{\mathrm{b}} \quad$ total base resistance

$Q_{\mathrm{s}} \quad$ total shaft friction

$q_{\mathrm{b}} \quad$ unit base resistance

$\boldsymbol{q}_{\mathrm{c}} \quad$ (unit) CPT tip resistance

$q_{\mathrm{c}, \text { local }}$ (unit) CPT tip resistance at pile base level (no weighting with depth)

$s \quad$ pile head settlement

Z depth

$z_{\mathrm{b}} \quad$ depth of embedment into hard layer

$\gamma \quad$ unit weight

\section{INTRODUCTION AND BACKGROUND}

In the past, this journal has published papers in which databases of load tests on displacement piles in sand have been collated and interpreted to provide new empirical approaches for design (e.g. References 1 and 2). These two papers noted that the distribution of friction along a pile shaft does not take the form assumed by conventional design methods. By assuming a more realistic distribution of shaft friction, the resulting new approaches in the above publications and others $^{3,4}$ offer improved reliability in design.

This paper considers the base resistance of closed-ended displacement piles in sand. A database of high-quality load tests has been examined. Ultimate base capacity, $\boldsymbol{q}_{\mathrm{b}}$, has been compared with CPT resistance, $q_{\mathrm{c}}$. No new empirical approach is proposed. Instead, it is shown that existing mechanisms of behaviour are sufficient to demonstrate a simple link between $q_{\mathrm{b}}$ and $\boldsymbol{q}_{\mathrm{c}}$.

A number of alternative methods exist to predict the unit base resistance, $\boldsymbol{q}_{\mathrm{b}}$, of a displacement pile in sand based on the results of a cone penetration test (CPT). The geometric similarity of piles and CPT instruments suggests that during steady penetration (or at the 'plunging' load* in a maintained load test), $\boldsymbol{q}_{\mathrm{b}}$ should equal $\boldsymbol{q}_{\mathrm{c}}$, as is predicted by continuum analysis methods such as cavity expansion solutions ${ }^{3}$ and the strain path method. ${ }^{5}$ However, a number of authors have suggested that reduction factors should be applied to cone resistance, $\boldsymbol{q}_{\mathrm{c}}$, such that $\boldsymbol{q}_{\mathrm{b}}=\alpha \boldsymbol{q}_{\mathrm{c}}$, where $\alpha<1$. These recommended reduction factors vary significantly. For example, Bustamante and Gianeselli ${ }^{6}$ suggest that $\alpha=0 \cdot 4-0 \cdot 5$ for sand and gravel, whereas de Ruiter and Beringen ${ }^{7}$ suggest that $\alpha$ ranges between 0.5 and 1 depending on overconsolidation ratio.

These reduction factors on $\boldsymbol{q}_{\mathrm{b}} / \boldsymbol{q}_{\mathrm{c}}$ can be linked to

(a) partial embedment $(L / D)$

(b) local inhomogeneity

(c) absolute pile diameter

(d) partial mobilisation

(e) residual stresses.

\section{I.I. Partial embedment (LID)}

As a pile has a greater diameter than a CPT instrument, a deeper embedment from the ground surface, or into a hard layer, is required to mobilise the 'full' strength of that layer.

"'Plunging' capacity is defined as the load at which continued penetration occurs without any further increase in resistance. Although not always reached in maintained load tests, this is a more fundamental measure of capacity than the load at a chosen settlement criterion, of which there are many, and which are influenced by pile stiffness as well as strength. 
Prior to sufficient penetration, $\boldsymbol{q}_{\mathrm{b}}$ will be less than $\boldsymbol{q}_{\mathrm{c}}$, as the previous layer will still be 'felt' by the pile tip. ${ }^{8,9}$ This mechanism is illustrated in Fig. 1.

Also, as the $L / D$ ratio of a CPT exceeds that of a pile, the ratio of shaft to base area is higher, and hence so is the ratio of $Q_{\mathrm{s}} / \boldsymbol{Q}_{\mathrm{b}}$. Analysis of the interaction between the shaft and base offers a mechanism by which the surcharge on the soil surrounding the base of a CPT is higher than around the base of a pile, leading to a corresponding decrease in $\boldsymbol{q}_{\mathrm{b}} / \boldsymbol{q}_{\mathrm{c}} .^{10,11}$

\section{I.2. Local inhomogeneity}

$\mathrm{Kraft}^{12}$ proposes that a reduction factor should be applied to account for local inhomogeneities. It is argued that the probability of pile base resistance being reduced by a local region of weak soil is higher than that of a CPT, owing to the larger volume of soil under consideration. However, this argument could be reversed by considering the influence of local regions of hard soil.

\section{I.3. Absolute pile diameter}

Jardine and Chow, ${ }^{4}$ in the MTD (Marine Technology

Directorate) design method for offshore piles, recommend a reduction factor for $\boldsymbol{q}_{\mathrm{b}} / \boldsymbol{q}_{\mathrm{c}}$ based on pile diameter. This was selected to provide a good fit with the database of high-quality load test results assembled by Chow ${ }^{13}$ (Fig. 2). The legend on this figure indicates the site of each load test. These sites are discussed later in this paper. This scale effect is linked to the formation of localised shear bands, and to compression of the pile shaft reducing the relative pile-soil movement at the tip. The Chow ${ }^{13}$ database is reassembled in this paper, and alternative conclusions are reached (Figs. 3 and 4).

Meyerhof ${ }^{14}$ and Tejchman and Gwizdala ${ }^{15}$ present pile load test data that show a reduction in unit base resistance with

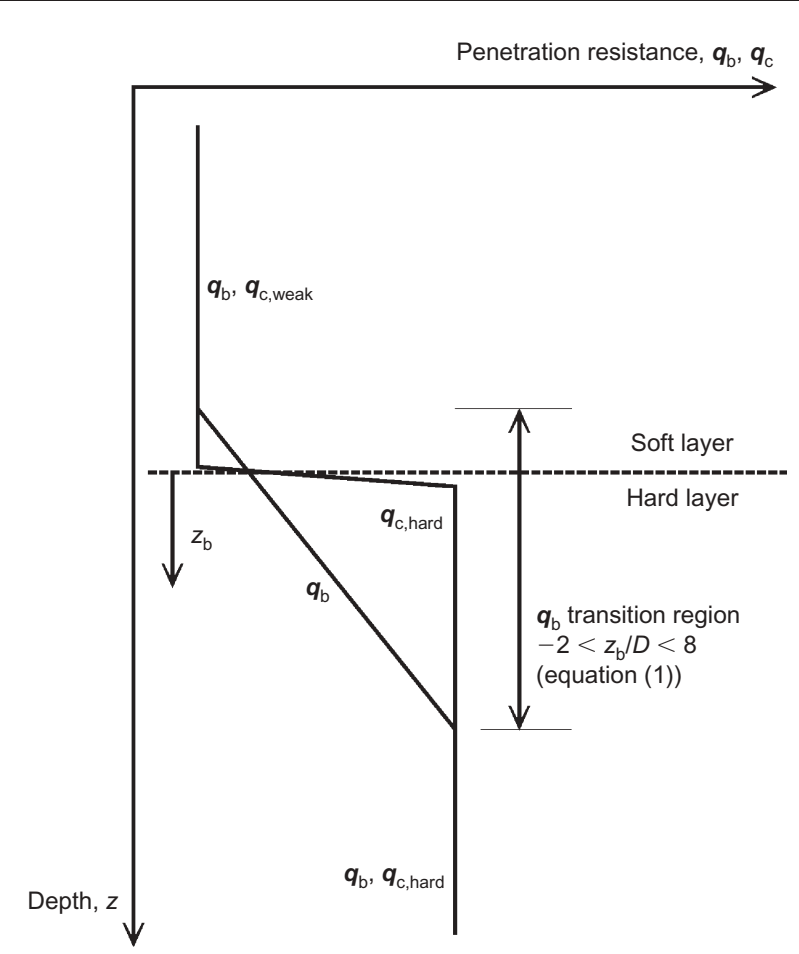

Fig. I. Partial embedment reduction factor on base resistance

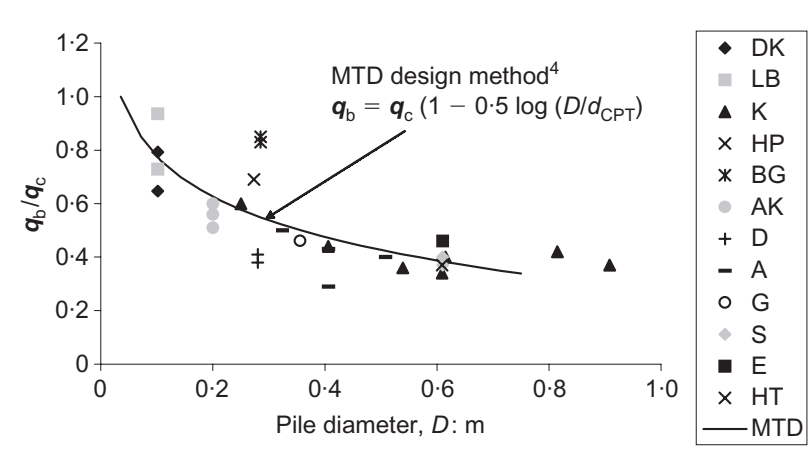

Fig. 2. Normalised pile base resistance plotted against pile diameter. ${ }^{13}$ Failure: D/I0 settlement

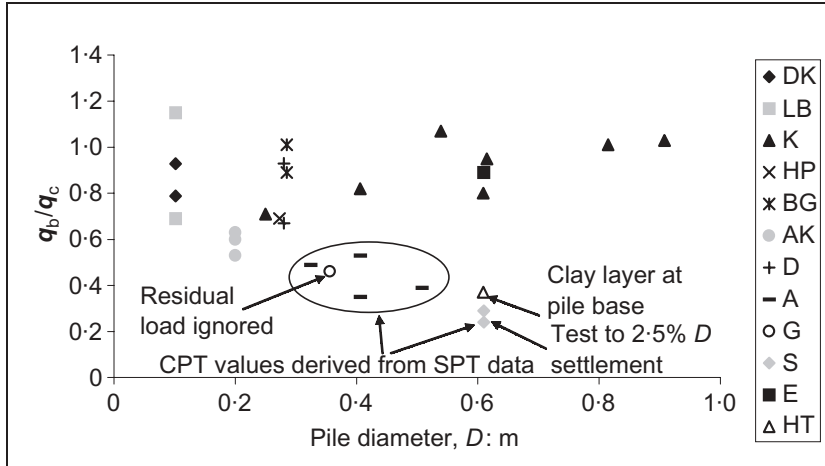

Fig. 3. Normalised pile base resistance plotted against pile diameter. ${ }^{32}$ Failure: $\mathrm{D} / \mathrm{I} 0$ settlement

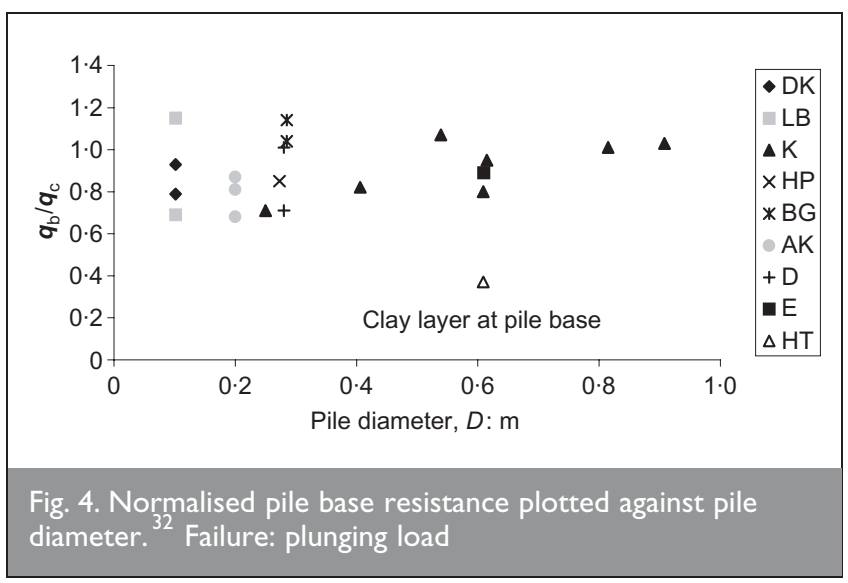

increasing pile diameter, although none of these load tests was of sufficient quality to enter the Chow ${ }^{13}$ database. The fullscale load test data presented by Tejchman and Gwizdala ${ }^{15}$ do not show the scale effect apparent in their model test data, although interpretation is hampered by the absence of soil property data to supplement the load test results.

One reason for rejection of this data from the Chow ${ }^{13}$ database is that much of the historical research comprised small-scale unit-gravity model tests. In these experiments the ambient stress level is typically less than $30 \mathrm{kPa}$. Under these laboratory conditions a scale effect on absolute diameter might be expected, in the same way that a scale effect on the size or width, $B$, of a shallow foundation has long been evident. ${ }^{16-18}$ This effect arises because the mean ambient stress level within the failure mechanism, taken as $\gamma B / 2$, is related to the diameter 
(or width) of the shallow foundation. Hence the bearing capacity factor $N_{\gamma}$ is introduced and an expression for bearing capacity, $\boldsymbol{q}_{\text {failure }}$ (ignoring contributions due to cohesion and surcharge), of the form $\boldsymbol{q}_{\text {failure }} /(\gamma B / 2)=N_{\gamma}$ is used. As angles of friction and dilation decrease sharply over the range of low to medium stresses, ${ }^{19}$ the resulting value of $N_{\gamma}$ reduces.

Graham and Hovan, ${ }^{20}$ Ueno et al. ${ }^{21}$ and Zhu et al. ${ }^{22}$ present stress characteristic analyses of shallow foundations using a stress-dependent friction angle to demonstrate this reduction of $N_{\gamma}$ with increasing foundation size, which are verified by centrifuge model tests. As the ambient stress and hence friction angle close to a field scale pile tip are related to pile length rather than diameter $(L>>D)$, this size effect mechanism is not applicable to piles.

A second mechanism that can lead to a size effect on shallow foundation bearing capacity is progressive failure along shear bands. As failure of a shallow foundation is approached, failure planes propagate from below the foundation to the ground surface. A short failure plane will mobilise peak strength along its entire length almost simultaneously. When the end of a longer failure plane is reaching peak strength, the start may have reduced to critical state strength. The integrated effect of this behaviour is for a reduced $N_{\gamma}$ factor to be recorded for a larger shallow foundation, ignoring variations in strength and dilatancy with stress level. This type of progressive failure, leading to a reduced peak resistance, has been observed inside shear boxes, ${ }^{23-25}$ and demonstrated analytically by Palmer et al. $^{26}$

A reduction factor due to progressive failure along slip planes is not applicable to deep foundations, as failure does not occur through the propagation of shear bands along planes of slip. Constructions of slip planes based on classical bearing capacity theory either are kinematically inadmissible, ${ }^{27}$ or

unrealistically predict bearing capacity to increase linearly with depth, often with shear bands extending to the ground surface. ${ }^{28}$ Model testing at a realistic ambient stress level reveals a continuum flow mechanism in which shear bands are not present. ${ }^{29,30}$ It could be argued that progressive failure can arise from anisotropy or a reduction in strength from peak to critical state during continuum deformation, but neither of these mechanisms involves a length scale and so could not lead to a reduction in base resistance with absolute pile diameter.

\section{I.4. Partial mobilisation}

Lee and Salgado ${ }^{31}$ present reduction factors on CPT resistance to account for partial mobilisation of $q_{\mathrm{b}}$ by noting that the definition of $\boldsymbol{q}_{\mathrm{b}}$ normally relates to a given settlement, rather than to the 'plunging' load required for continued penetration. Finite-element analysis is used to compare the proportion of ultimate pile capacity (which equals $q_{\mathrm{c}}$, and is found by a cavity expansion method) mobilised at typical working settlements.

\section{I.5. Residual stresses}

In addition, low apparent values of $\boldsymbol{q}_{\mathrm{b}}$ arise if residual stresses are ignored. After the final blow or jacking stroke of installation the pile head rebounds. A larger displacement is required to unload the pile base than to reverse the shaft friction. Therefore, when the pile head reaches a state of equilibrium with the (zero) applied head load, the lower part of the pile remains in compression. A proportion of the base load is 'locked in', and balanced by negative shaft friction on the lower part of the shaft. It is common practice to re-zero pile instrumentation prior to a load test, to remove the influence of any instrument drift during driving. This leads to an underprediction of base resistance and an overprediction of shaft friction. Load tests on a jacked instrumented pile reported by Chow ${ }^{13}$ showed that approximately 50\% of the ultimate base capacity was present as residual stress prior to load testing (Fig. 6). Load test results for displacement piles in which an initial base load of zero is reported should be treated with caution; a significant underestimate of $\boldsymbol{q}_{\mathrm{b}}$ is likely.
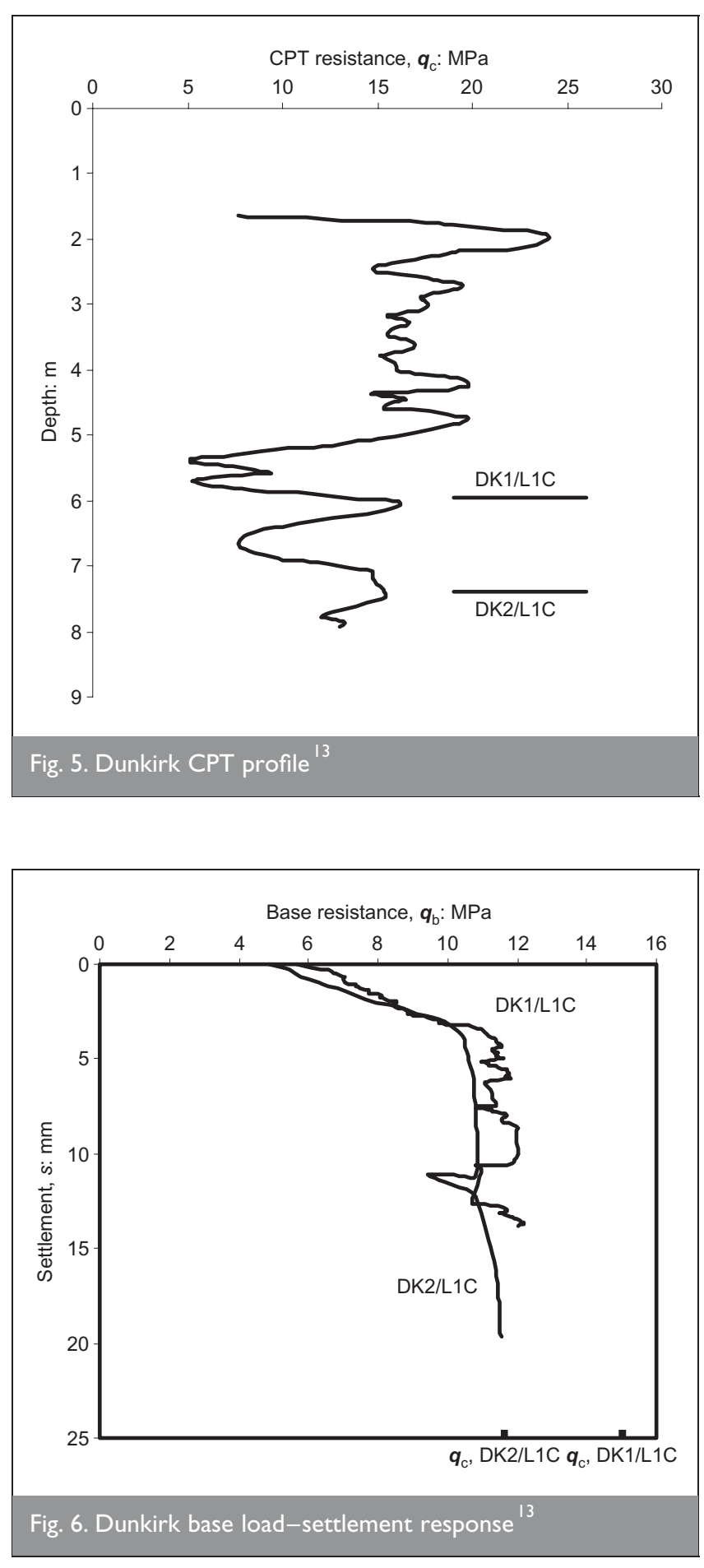

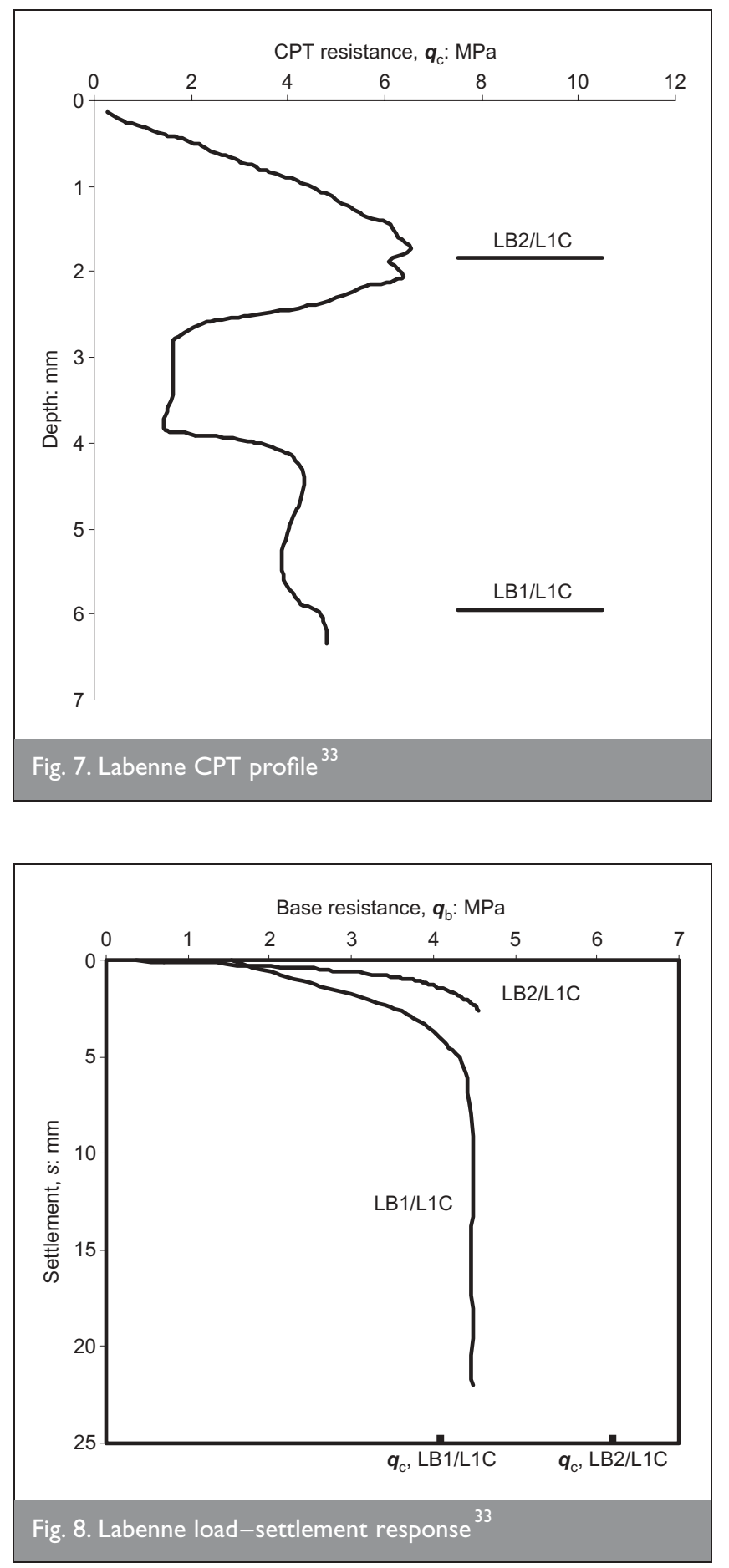

In order to shed light on these possible differences between $\boldsymbol{q}_{\mathrm{c}}$ and $\boldsymbol{q}_{\mathrm{b}}$, the database of compression load test results from closed-ended displacement piles in sand assembled by Chow ${ }^{13}$ has been re-evaluated from the original sources. The Chow database comprises open- and closed-ended displacement piles in clay and sand. It has been selected as the basis for this paper as it represents the largest database of high-quality pile load tests in the literature. This paper is concerned only with closedended piles in sand, for which field load test data from 28 pile tests at 12 sites were collated by Chow. For this paper, the original sources have been used to examine more closely the relationship between CPT and base resistance. The CPT soundings and load tests results are reproduced in the Appendix. Additional notes discussing the original references and the extraction of $\boldsymbol{q}_{\mathrm{b}}$ and $\boldsymbol{q}_{\mathrm{c}}$ from the historical records are

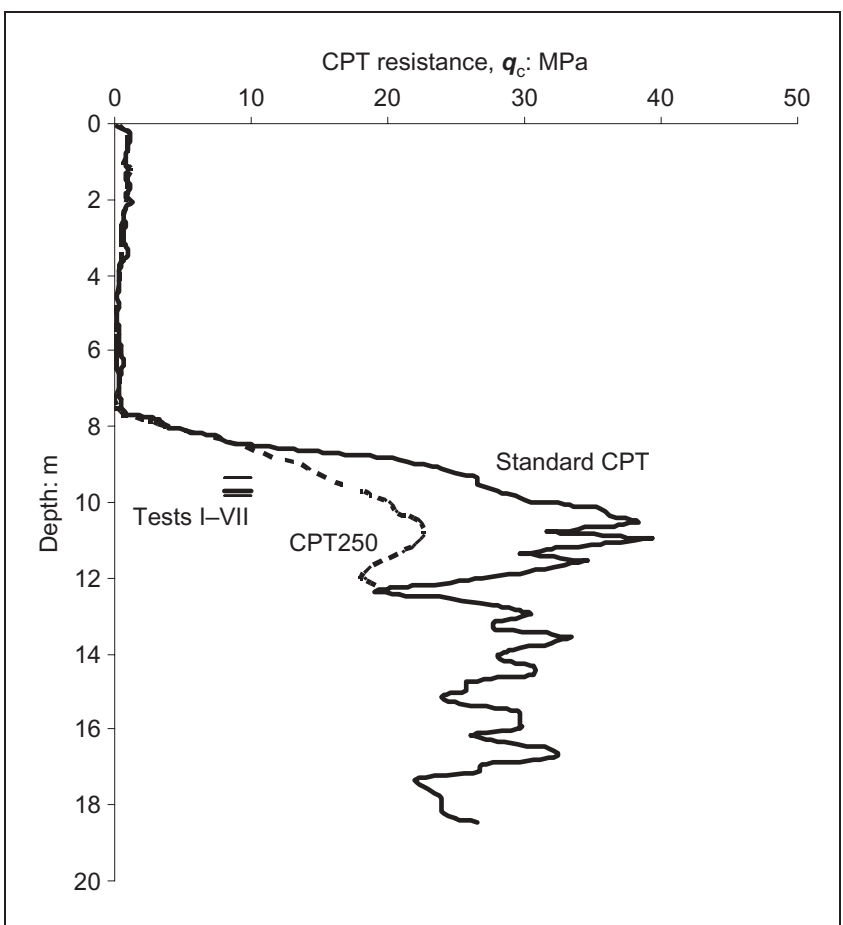

Fig. 9. Kallo CPT profile ${ }^{34}$

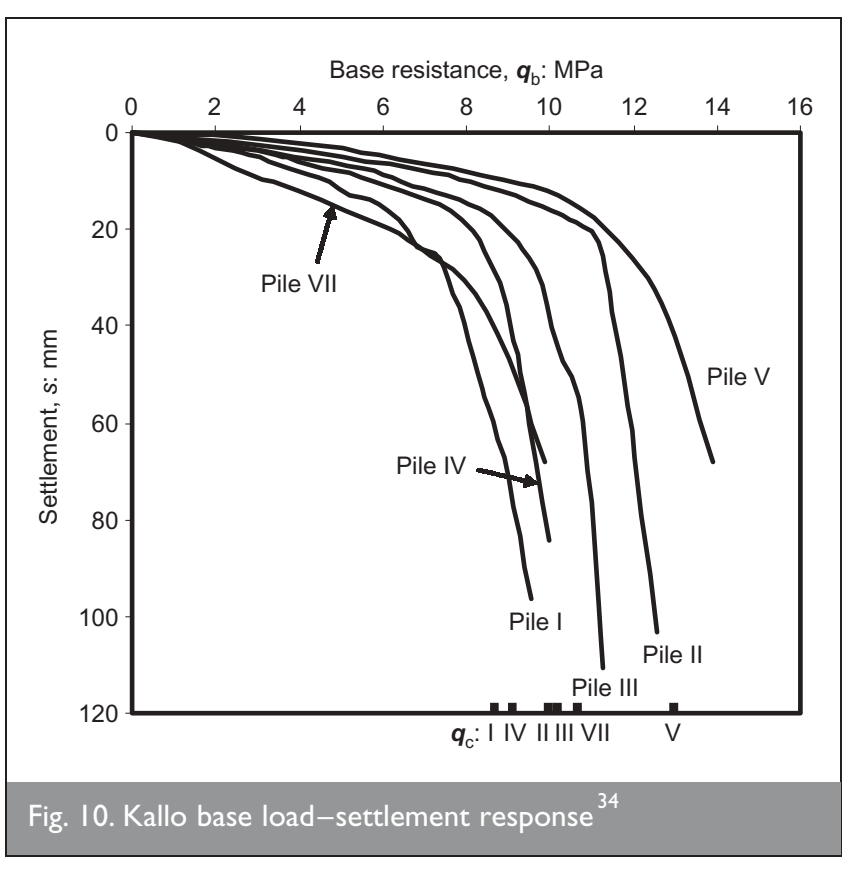

given in Reference 32. Owing to space limitations only key details are presented herein.

Unit base resistance, $q_{\mathrm{b}}$, has been evaluated according to two failure criteria: $D / 10$ pile head settlement (as used in the Chow database), and 'plunging' failure. 'Plunging' capacity is clearly defined in some tests, for which a constant penetration resistance was clearly reached. In other cases, where nearconstant penetration resistance is reached, the maximum applied load has been chosen. This represents an underestimate, which in most cases is by only a few per cent if compared with an extrapolated curve. For each site the method of evaluating plunging capacity has been stated. CPT resistance, $\boldsymbol{q}_{\mathrm{c}}$, has been evaluated following Chow ${ }^{13}$ by averaging $q_{\mathrm{c}}$ over 1.5 pile diameters above and below the pile tip, with the exception of 
$\boldsymbol{q}_{\mathrm{c}}$ at the Kallo and Lower Arrow Lake sites, for which a correction for partial embedment has been applied.

\section{FIELD MEASUREMENTS}

\section{I. Site I: Dunkirk ${ }^{13}$ (DK), Site 2: Labenne ${ }^{33}$ (LB)}

Four compression tests on the Imperial College jacked instrumented pile reported by Lehane ${ }^{33}$ and Chow ${ }^{13}$ are summarised in Table 1.

\subsection{Site 3: $\mathrm{Kallo}^{34}$ (K)}

Six compression load tests on Franki-piles with expanded concrete bases are reported by De Beer et al., ${ }^{34}$ plus a large (250 mm diameter) CPT probe (Table 2). All tests were conducted at a shallow embedment $(<1.6 \mathrm{~m})$ into dense sand underlying soft clay and peat. The interface between these strata lies at a depth of approximately $8.2 \mathrm{~m}$, and is characterised by an approximately 50 -fold change in CPT resistance.

De Beer et al.'s paper ${ }^{34}$ focuses on the effect of such shallow embedment into a bearing stratum. This point is not considered by Chow, ${ }^{13}$ who uses the Kallo data to validate the Jardine and Chow ${ }^{4}$ design approach, which alternatively features a scale effect on absolute diameter (not normalised by embedment). The 'full' $\boldsymbol{q}_{\mathrm{b}}$ available in the dense sand is not mobilised in the case of shallow embedment, as the overlying soft soil is still 'felt' by the pile base. The local $q_{\mathrm{c}}$ must be scaled down accordingly.

In this paper a scaling procedure for two-layer soil based on the approach described by Meyerhof and Valsangkar ${ }^{8,9}$ has been used to select an appropriate average $\boldsymbol{q}_{\mathrm{c}}$ based on the two strata for a pile embedded at depth $z_{\mathrm{b}}$ into a hard stratum. The strata at Kallo have been idealised as having uniform $q_{\mathrm{c}}$ of
0.5 MPa and $25 \mathrm{MPa}$ respectively, to allow this simple calculation method to be used (see Appendix, Fig. 9). A linear variation in corrected $\boldsymbol{q}_{\mathrm{c}}$ over 10 pile diameters beginning two diameters above the hard layer has been chosen, based on References 8 and 9, which indicate that the zone of influence extends between zero and four diameters above the strata interface (equation (1), Fig. 1).

It should be noted that the resulting values of mean $\boldsymbol{q}_{\mathrm{c}}$ in Table 2 are very sensitive to the level at which the influence of the hard layer is first felt (taken as $2 D$ in this case), owing to the high strength differential at this site.

$\boldsymbol{q}_{\mathrm{c}, \text { corrected }}=\boldsymbol{q}_{\mathrm{c}, \text { weak }}+\frac{\left(\boldsymbol{q}_{\mathrm{c} \text {,hard }}-\boldsymbol{q}_{\mathrm{c}, \text { weak }}\right)\left(\frac{z_{\mathrm{b}}}{D}+2\right)}{10}$
for $-2<\frac{z_{\mathrm{b}}}{D}<8$

\subsection{Site 4: Hunter's Point ${ }^{35}$ (HP)}

The maintained load test on a single closed-ended steel tubular pile hammer driven into sand reported by Briaud et al. ${ }^{35}$ is included in the database (Table 3).

\subsection{Site 5: Baghdad $^{\text {36, } 37}$ (BG)}

The database includes compression tests on two driven square precast concrete piles carried out in Baghdad (Table 3). Correction for residual stresses was carried out in the original references, following Fellenius. ${ }^{38}$

\subsection{Site 6: Akasaka $^{39}$ (AK)}

Three load tests on instrumented steel closed-ended piles from the research programme reported by the BCP Committee ${ }^{39}$ are included in the Chow ${ }^{13}$ database (Table 3). In tests $1 \mathrm{C}$ and $6 \mathrm{~B}$ the pile was installed by

\begin{tabular}{|lccll}
\hline Test & DKI/LIC & DK2/LIC & LBI/LIC & LB2/LIC \\
\hline Diameter: $m$ & 0.1016 & 0.1016 & 0.1016 & 0.1016 \\
Pile tip depth: $m$ & 7.40 & 5.96 & 5.95 & 1.83 \\
$\boldsymbol{q}_{\mathrm{c}}$ (av. $\left.\pm 1.5 D\right):$ MPa & 15.03 & 11.68 & 4.1 & 6.2 \\
$\boldsymbol{q}_{\mathrm{b}}(\mathrm{D} / \mathrm{IO}$ failure): MPa & 11.85 & 10.85 & 4.7 & 4.3 \\
$\boldsymbol{q}_{\mathrm{b}} / \boldsymbol{q}_{\mathrm{c}}(\mathrm{D} / \mathrm{IO}$ failure) & 0.788 & 0.929 & 1.15 & 0.69 \\
$\boldsymbol{q}_{\mathrm{b}}$ (plunging failure): MPa & 11.85 & 10.85 & 4.7 & 4.3 \\
$\boldsymbol{q}_{\mathrm{b}} / \boldsymbol{q}_{\mathrm{c}}$ (plunging failure) & 0.788 & 0.929 & 1.15 & 0.69
\end{tabular}

Table I. Dunkirk and Labenne data jacking. Test 6C was hammer driven. The tests were conducted with the tip of the pile at a shallow embedment into a hard layer, although a sharp transition into this stratum is not clear from the CPT profile, preventing any correction for partial embedment following equation (1) (see Appendix, Fig. 14). SPT $N$-values of 30

\begin{tabular}{|c|c|c|c|c|c|c|c|}
\hline Test & СРT250 & 1 & II & III & IV & V & VII \\
\hline Diameter: $\mathrm{m}$ & 0.25 & 0.908 & 0.539 & 0.615 & 0.815 & 0.406 & 0.609 \\
\hline Pile tip depth: $m$ & & 9.69 & $9 \cdot 71$ & $9 \cdot 82$ & 9.80 & $9 \cdot 33$ & $9 \cdot 37$ \\
\hline Embedment, $z_{\mathrm{b}} / D$ & $5 \cdot 0$ & 1.41 & 1.97 & 2.06 & 1.60 & $3 \cdot 22$ & $2 \cdot 25$ \\
\hline $\boldsymbol{q}_{\mathrm{c}}: \mathrm{MPa}$ & $17 \cdot 65$ & $8 \cdot 68$ & $10 \cdot 0$ & $10 \cdot 2$ & $9 \cdot 14$ & $13 \cdot 0$ & $10 \cdot 7$ \\
\hline $\boldsymbol{q}_{\mathrm{b}}(\mathrm{D} / \mathrm{I} 0$ failure $): \mathrm{MPa}$ & $12 \cdot 6$ & 8.96 & $10 \cdot 7$ & $9 \cdot 73$ & $9 \cdot 22$ & 10.7 & $8 \cdot 55$ \\
\hline $\boldsymbol{q}_{\mathrm{b}} / \boldsymbol{q}_{\mathrm{c}}(\mathrm{D} / \mathrm{I} 0$ failure $)$ & 0.71 & 1.03 & 1.07 & 0.95 & 1.01 & 0.82 & 0.80 \\
\hline $\boldsymbol{q}_{\mathrm{b}}$ (plunging failure): $\mathrm{MPa}$ & $12 \cdot 6$ & 8.96 & 10.7 & $9 \cdot 73$ & $9 \cdot 22$ & $10 \cdot 7$ & 8.55 \\
\hline $\boldsymbol{q}_{\mathrm{b}} / \mathbf{q}_{\mathrm{c}}$ (plunging failure) & 0.71 & 1.03 & 1.07 & 0.95 & 1.01 & 0.82 & 0.80 \\
\hline
\end{tabular}




\begin{tabular}{|c|c|c|c|c|c|c|}
\hline Test & $\begin{array}{c}\text { Hunter's Point } \\
\text { HPI }\end{array}$ & $\begin{array}{l}\text { Baghdad } \\
\text { Pile I }\end{array}$ & $\begin{array}{l}\text { Baghdad } \\
\text { Pile } 2\end{array}$ & $\begin{array}{l}\text { Akasaka } \\
\text { IC }\end{array}$ & $\begin{array}{c}\text { Akasaka } \\
\text { 6B }\end{array}$ & $\begin{array}{c}\text { Akasaka } \\
\text { 6C }\end{array}$ \\
\hline Diameter: $\mathrm{m}$ & 0.273 & 0.285 & 0.285 & $0 \cdot 20$ & 0.20 & 0.20 \\
\hline Pile tip depth: $m$ & $7 \cdot 78$ & 11.0 & $15 \cdot 0$ & 11.0 & 4.0 & 11.0 \\
\hline $\boldsymbol{q}_{\mathrm{c}}($ av. \pm I.5D): $\mathrm{MPa}$ & $7 \cdot 2$ & $6 \cdot 0$ & 6.6 & $29 \cdot 8$ & 8.06 & $29 \cdot 8$ \\
\hline$q_{\mathrm{b}}$ (D/I0 failure): $\mathrm{MPa}$ & 4.94 & $5 \cdot 36$ & $7 \cdot 29$ & 17.83 & $4 \cdot 3$ & 18.78 \\
\hline $\boldsymbol{q}_{\mathrm{b}} / \boldsymbol{q}_{\mathrm{c}}(\mathrm{D} / \mathrm{I} 0$ failure $)$ & 0.69 & 0.89 & $1 \cdot 10$ & 0.60 & 0.53 & 0.63 \\
\hline$q_{\mathrm{b}}$ (plunging failure): $\mathrm{MPa}$ & $6 \cdot 13$ & $6 \cdot 21$ & $7 \cdot 52$ & 26.08 & $6 \cdot 37$ & $20 \cdot 37$ \\
\hline $\boldsymbol{q}_{\mathrm{b}} / \boldsymbol{q}_{\mathrm{c}}$ (plunging failure) & 0.85 & 1.04 & $1 \cdot 14$ & 0.87 & 0.81 & 0.68 \\
\hline
\end{tabular}

Table 3. Hunter's Point, Baghdad and Akasaka data

and $>60$ were recorded at depths of 10.5 and $12.5 \mathrm{~m}$ respectively. CPT probes ended (or reached refusal) at a depth of $11.5 \mathrm{~m}$.

\subsection{Site 7. Drammen ${ }^{40}$ (D)}

Two compression tests on an instrumented precast cylindrical concrete pile are reported by Gregersen et al. ${ }^{40}$ (Table 4). Strain gauges were used to measure residual loads directly, although zero drift was observed. During load testing, $\boldsymbol{Q}_{\mathrm{s}}$ in compression appears to be $50-100 \%$ greater than in tension (see Fig. 5 in Reference 40), indicating that residual stresses may be present, leading to an underestimate of $\boldsymbol{Q}_{\mathrm{b}}$ (and an overestimate of $\boldsymbol{Q}_{\mathrm{s}}$ in compression), as noted by Chow. ${ }^{13}$ In addition, during each stage of the load test, shaft friction does not reach a limiting value, even at high settlement. This suggests that some component of base resistance is included in the recorded shaft friction.

In this analysis, a simple attempt has been made to correct for residual stresses, by assuming that $\boldsymbol{Q}_{\mathrm{S}}$ is equal in compression and in tension. The difference between $\boldsymbol{Q}_{\mathrm{S}}$ in compression and in tension, linked by De Nicola and Randolph ${ }^{41}$ to Poisson's strains and by Lehane et al. ${ }^{42}$ to the rotation of the principal stress direction, has been ignored in this simple analysis. The plunging capacity is difficult to establish, as regular unloadreload loops interrupt the development of ultimate load. The capacity is increasing at the end of each loop. The maximum applied load has been used as plunging capacity, which is likely to be a 5-15\% underprediction of the correct value, and similar to any overprediction arising from the assumption that $\boldsymbol{Q}_{\mathrm{S}}$ is equal in compression and tension.

\subsection{Site 8. Arkansas ${ }^{43,44}$ (A)}

Four of the compression load tests reported by Mansur and Hunter ${ }^{43}$ are included in the Chow ${ }^{13}$ database, using the corrections made for residual stresses by Coyle and Castello ${ }^{44}$ (Table 4). The Coyle and Castello ${ }^{44}$ values of relative density, $D_{\mathrm{r}}$, have been used to infer CPT resistance following Lunne and Christoffersen. $^{45}$

Load-settlement curves are not available for tests 1 and 3 . The load-settlement curve for test 2 indicates a continuing increase in capacity beyond $s=D / 10$, preventing reliable estimation of the 'plunging' load. Test 10 was halted prior to settlement of D/10 (Coyle and Castello extrapolate this curve to estimate $D / 10$ capacity). Therefore plunging load has not been estimated for this paper.

\subsection{Site 9: Hoogzand ${ }^{46}$ (G)}

A single load test on a closed-ended pipe pile reported by Beringen et al. ${ }^{46}$ is summarised in Table 5 . Chow ${ }^{13}$ notes that, in the conference discussion, the authors state that residual loads were corrected for, even though the shapes of the shear stress distributions suggest otherwise. Furthermore, a base load measurement of zero is recorded at the start of the compression load test, indicating that any residual load has been ignored (see Appendix, Fig. 18). The value of $q_{\mathrm{b}}$ was continuing to increase steadily at the end of the test, so no plunging capacity has been inferred.

\subsection{Site 10: $\mathrm{H} \sin \mathrm{Ta}^{47}$ (HT)}

Three load tests are reported on $609 \mathrm{~mm}$ diameter closed-ended pipe piles (Table 5). One test pile, designated TP4, was loaded in compression to failure. A borehole log at the location of TP4

\begin{tabular}{|c|c|c|c|c|c|c|}
\hline Test & $\begin{array}{c}\text { Drammen } \\
\text { Pile A }\end{array}$ & $\begin{array}{c}\text { Drammen } \\
\text { Pile D/A }\end{array}$ & $\begin{array}{c}\text { Arkansas } \\
\text { Pile I }\end{array}$ & $\begin{array}{c}\text { Arkansas } \\
\text { Pile } 2\end{array}$ & $\begin{array}{c}\text { Arkansas } \\
\text { Pile } 3\end{array}$ & $\begin{array}{c}\text { Arkansas } \\
\text { Pile } 10\end{array}$ \\
\hline Diameter: m & 0.28 & 0.28 & 0.324 & 0.406 & 0.508 & 0.406 \\
\hline Pile tip depth: $m$ & 8.00 & 16.00 & $16 \cdot 18$ & 16.09 & $16 \cdot 15$ & $16 \cdot 15$ \\
\hline $\left.\boldsymbol{q}_{\mathrm{c}}(\mathrm{av} . \pm \mathrm{I} \cdot 5 \mathrm{D}): \mathrm{MPa}\right)$ & $2 \cdot 80$ & $5 \cdot 10$ & 16.47 & $12 \cdot 5 \mid$ & 16.45 & $12 \cdot 52$ \\
\hline $\boldsymbol{q}_{\mathrm{b}}(\mathrm{D} / \mathrm{I} 0$ failure $): \mathrm{MPa}$ & $2 \cdot 61$ & $3 \cdot 43$ & 8.01 & 6.66 & 6.46 & $4 \cdot 44$ \\
\hline $\boldsymbol{q}_{b} / \boldsymbol{q}_{c}(D / / 0$ failure $)$ & 0.93 & 0.67 & 0.49 & 0.53 & 0.39 & 0.35 \\
\hline $\boldsymbol{q}_{\mathrm{b}}$ (plunging failure): $\mathrm{MPa}$ & $2 \cdot 84$ & $3 \cdot 61$ & & & & \\
\hline $\boldsymbol{q}_{\mathrm{b}} / \boldsymbol{q}_{\mathrm{c}}$ (plunging failure) & 1.01 & 0.71 & & & & \\
\hline
\end{tabular}




\begin{tabular}{|c|c|c|c|c|c|}
\hline Test & Hoogzand & Hsin Ta TP4 & Seattle Pile A & Seattle Pile B & Lower Arrow Lake \\
\hline Diameter: $\mathrm{m}$ & 0.356 & 0.609 & 0.61 & 0.61 & 0.61 \\
\hline Pile tip depth: $\mathrm{m}$ & 6.75 & $34 \cdot 25$ & $29 \cdot 9$ & $25 \cdot 6$ & $47 \cdot 24$ \\
\hline $\boldsymbol{q}_{\mathrm{c}}(\mathrm{av} . \pm 1 \cdot 5 \mathrm{D}): \mathrm{MPa}$ & $28 \cdot 7$ & $7 \cdot 9$ & $13 \cdot 3$ & $13 \cdot 3$ & 10.8 \\
\hline $\boldsymbol{q}_{\mathrm{b}}(\mathrm{D} / \mathrm{I} 0$ failure $): \mathrm{MPa}$ & $13 \cdot 3$ & $2 \cdot 92$ & 3.83 & $3 \cdot 21$ & $9 \cdot 58$ \\
\hline $\boldsymbol{q}_{\mathrm{b}} / \boldsymbol{q}_{\mathrm{c}}(\mathrm{D} / \mathrm{I} 0$ failure $)$ & 0.46 & 0.37 & 0.29 & 0.24 & 0.89 \\
\hline $\mathbf{q}_{\mathrm{b}}$ (plunging failure): $\mathrm{MPa}$ & & $2 \cdot 92$ & & & $9 \cdot 58$ \\
\hline $\boldsymbol{q}_{\mathrm{b}} / \boldsymbol{q}_{\mathrm{c}}$ (plunging failure) & & $0 \cdot 37$ & & & 0.89 \\
\hline
\end{tabular}

indicates that the pile base was located within a $1.5 \mathrm{~m}$ thick layer of clay (see Fig. 1 in Reference 47). Boreholes corresponding to the other test pile locations (55-70 m distant) show that the depths at which clay is present vary across the site. CPT probes conducted for other test piles show a reduction in $\boldsymbol{q}_{\mathrm{c}}$ to 2-3 $\mathrm{MPa}$ within the clay layers. However, the CPT probe closest to pile TP4 does not capture a reduction in $q_{\mathrm{c}}$ at the level of the pile base (despite the presence of a clay layer in the borehole $\log$ at TP4) and so may not give an appropriate value (see Appendix, Fig. 19). The exact location of the CPT probe compared with pile TP4 and the borehole is not stated. The shape of the pile head load-settlement curve for TP4 shows the load at $D / 10$ settlement to be comparable to plunging capacity.

\subsection{Site I I: Seattle ${ }^{48}$ (S)}

Two compression tests on octagonal concrete precast piles of nominal 24 in $(608 \mathrm{~mm})$ diameter are reported (Table 5).

Residual stresses are estimated from base load measurements of a nearby identical pile. This residual base load is approximately $12 \%$ of the back-analysed shaft capacity of the test piles. This is a surprisingly small proportion of shaft friction to have been retained after driving as a residual base load, suggesting that this value is an underestimate. The piles were tested to a settlement of $2 \cdot 5 \%$ of $D$, which could account for the low

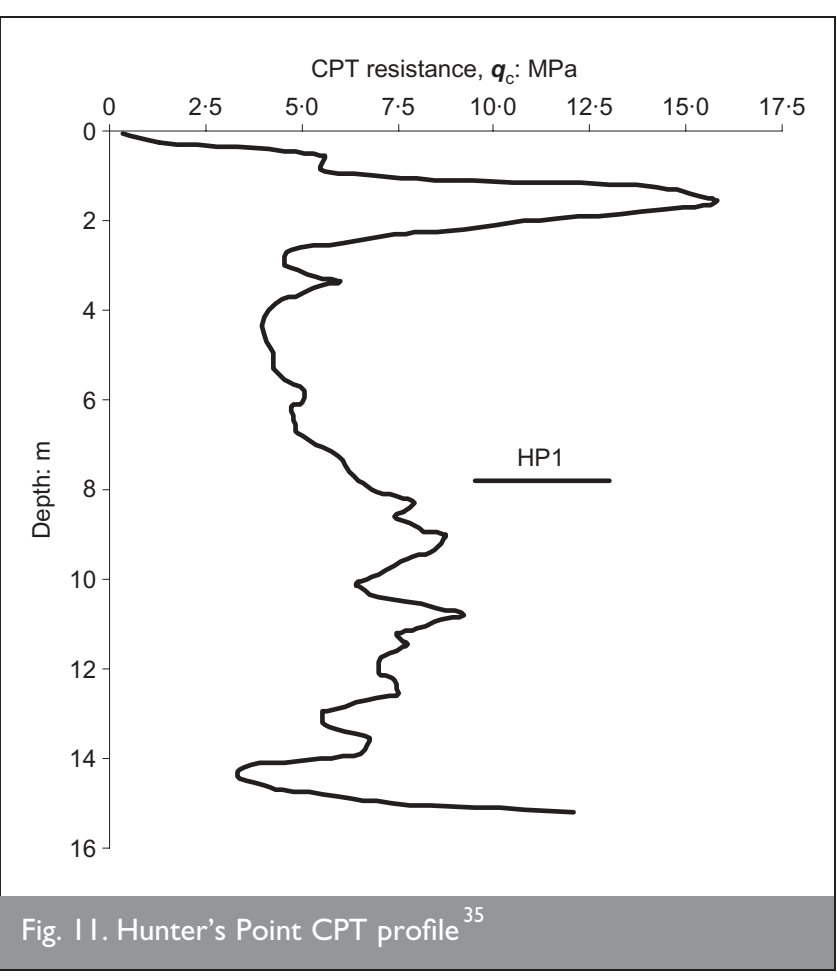

measured base resistance; $D / 40$ has been used as the failure criterion. CPT resistance was estimated following Burland and Burbidge $^{49}$ (as cited in Reference 50). A mean value of $N=40$ is found below $9 \mathrm{~m}$ depth. ${ }^{48}$

\subsection{Site 12: Lower Arrow Lake ${ }^{51}$ (E)}

A compression load test was conducted on a steel pipe pile driven open-ended with regular coring of the soil plug (Table 5). The pile was filled with a concrete plug after first being loaded to measure shaft friction alone. The tip of the pile was embedded a short distance into a layer of fine dense silty sand (SPT $N$-value 49 ) overlain by clayey silt (SPT $N$-value 8 ) (see Fig. 2 in Reference 51).

The borehole log indicates that the dense sand layer begins at a depth of $144 \mathrm{ft}(43.9 \mathrm{~m})$, although the driving record of the pile does not show a significant increase in resistance at this point. Instead, a sharp increase in driving resistance is apparent at around $149 \mathrm{ft}(45.4 \mathrm{~m})$, although it is not clear whether this is prior or subsequent to construction of the concrete plug. During further driving of the now closed-ended pile a sharp increase in driving resistance commensurate with the transition into dense sand is apparent at a depth of $153 \mathrm{ft}(46 \cdot 6 \mathrm{~m})$.

The site cross-section shows the top of the dense layer to be sloping at a gradient of $1: 8$, but the borehole location is not shown. Were the borehole to lie $50 \mathrm{ft}(15.2 \mathrm{~m})$ 'uphill' of the

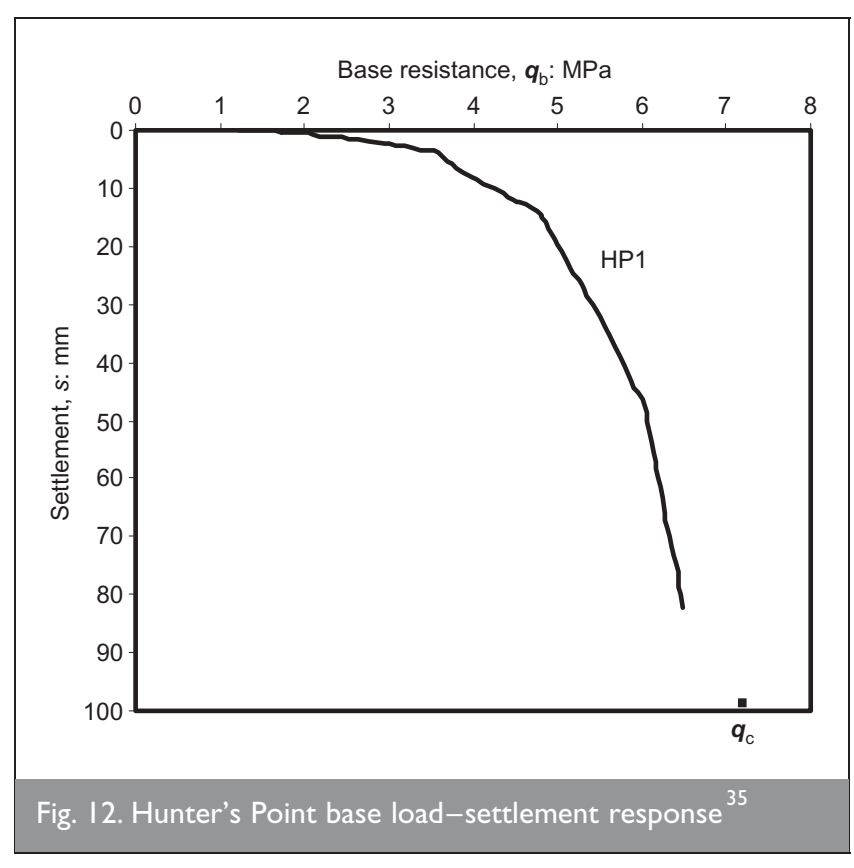



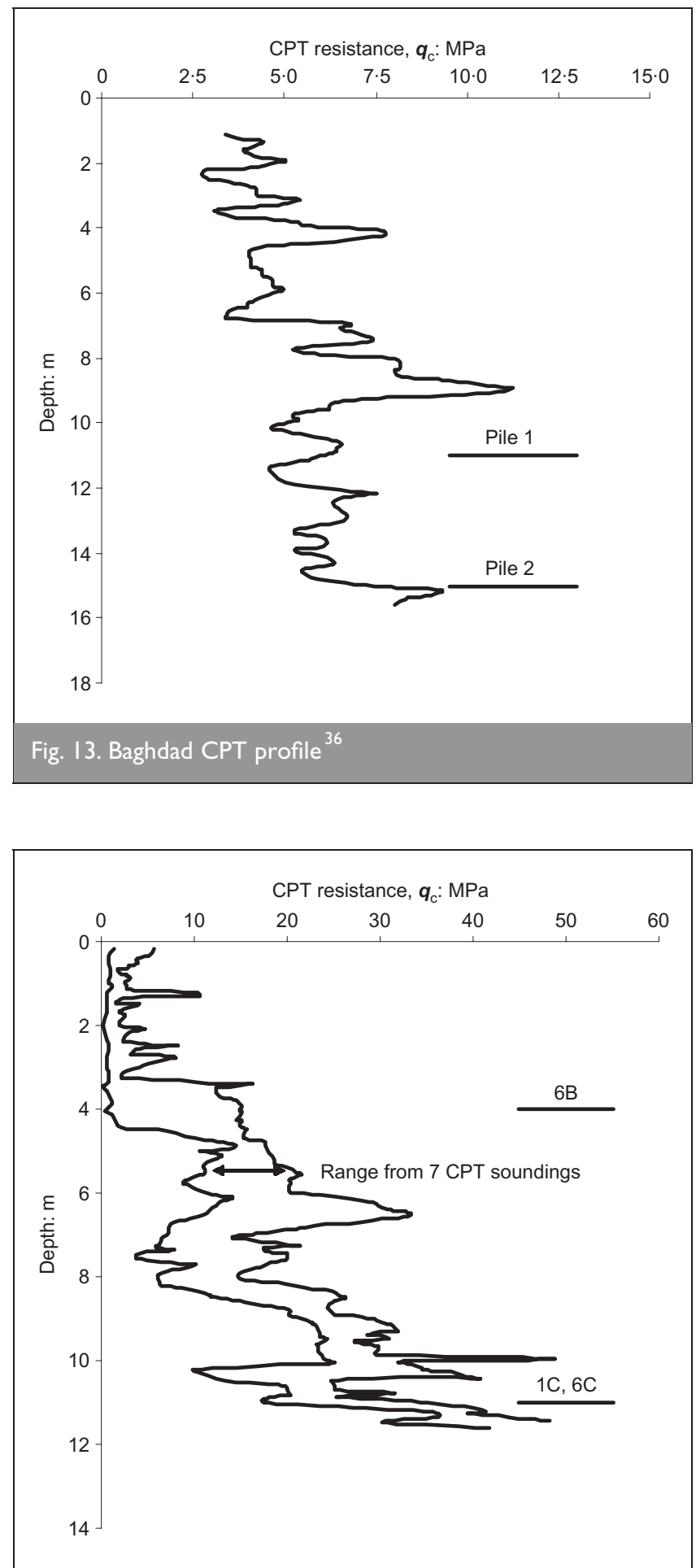

Fig. 14. Akasaka CPT profile

test pile, the sand layer could lie at a depth of $149 \mathrm{ft}$ at the pile location rather than the $144 \mathrm{ft}$ shown in the borehole log, as could be tentatively assumed from the driving record. This would place the pile tip at an embedment of $6 \mathrm{ft}(1 \cdot 8 \mathrm{~m})$, or three pile diameters, into the dense sand layer, for which some correction due to partial embedment into the bearing stratum should be applied (equation (1), Fig. 1).

CPT data are not available, so SPT values have been converted following Burland and Burbidge. ${ }^{49}$ Using equation (1), an appropriate mean value of $\boldsymbol{q}_{\mathrm{c}}$ at an embedment of three pile diameters into the dense sand is $10 \cdot 8 \mathrm{MPa}$.

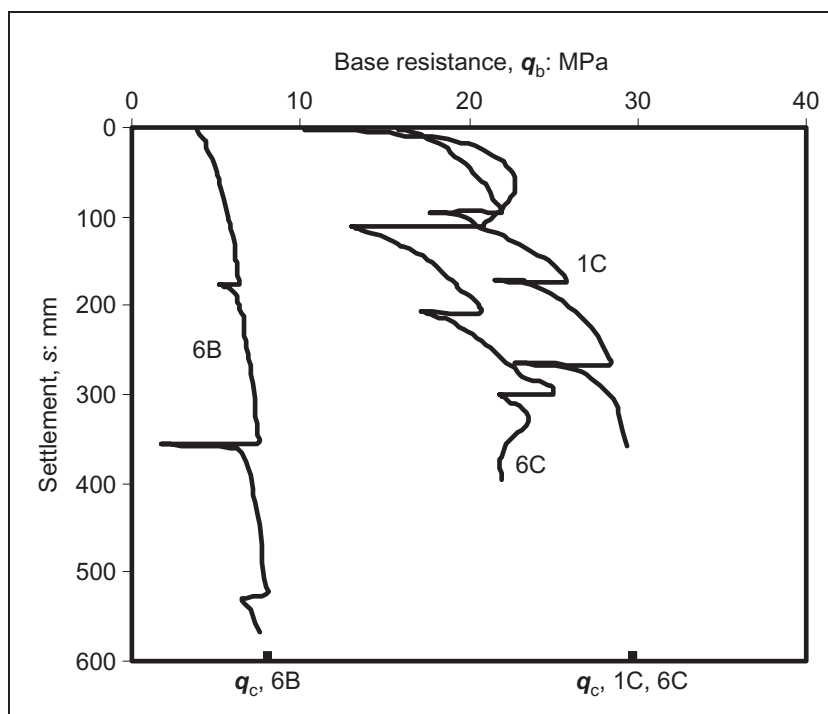

Fig. 15. Akasaka base load-settlement response ${ }^{39}$

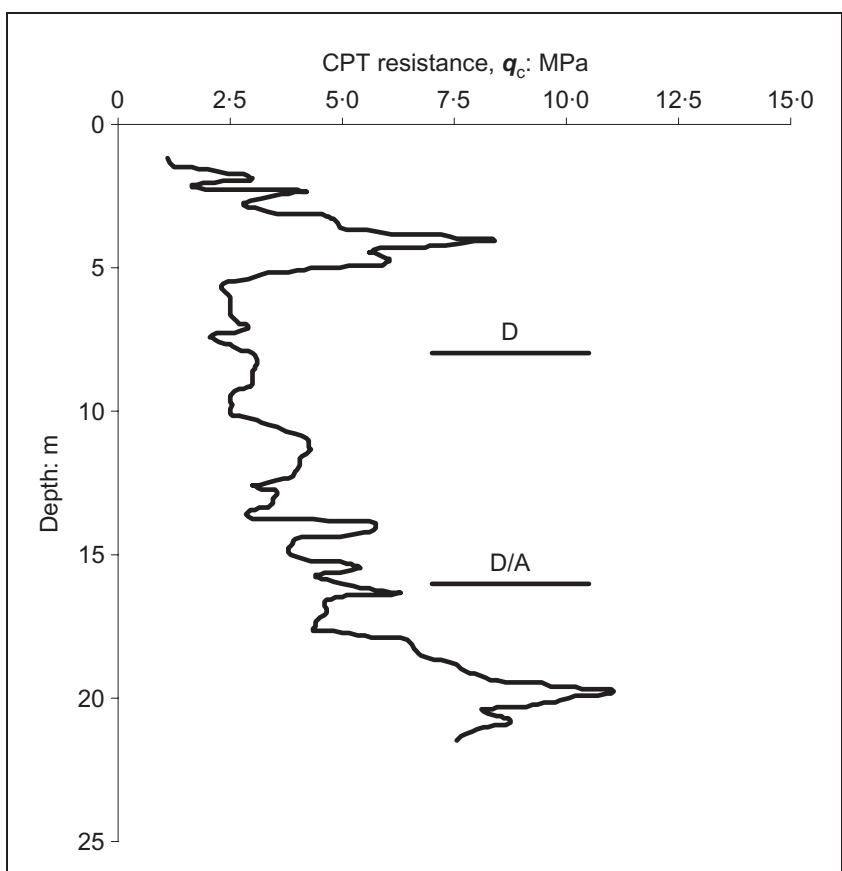

Fig. 16. Drammen CPT profile ${ }^{40}$

Base capacity is derived by subtracting the shaft capacity measured in the initial open-ended test from the total load measured after construction of the concrete plug. The $500 \mathrm{t}$ capacity of the loading rig was reached at a pile head settlement of 2.5 in $(63 \mathrm{~mm})(D / 10=2.4$ in $(61.0 \mathrm{~mm}))$. Extrapolation of the load-settlement curve suggests that plunging load was almost reached; $D / 10$ values have been used as a conservative estimate.

\section{DISCUSSION}

The load test data of $\boldsymbol{q}_{\mathrm{b}} / \boldsymbol{q}_{\mathrm{c}}$ as used to validate the Jardine and Chow ${ }^{4}$ design method for base resistance on closed-ended piles in sand are shown in Fig. 2. The same data interpreted as described in this paper are shown in Figs 3 and 4, for which $D / 10$ settlement (as used by Jardine and Chow ${ }^{4}$ ) and 'plunging' have been used to define failure respectively. The scale effect on absolute diameter is not apparent when the data are 

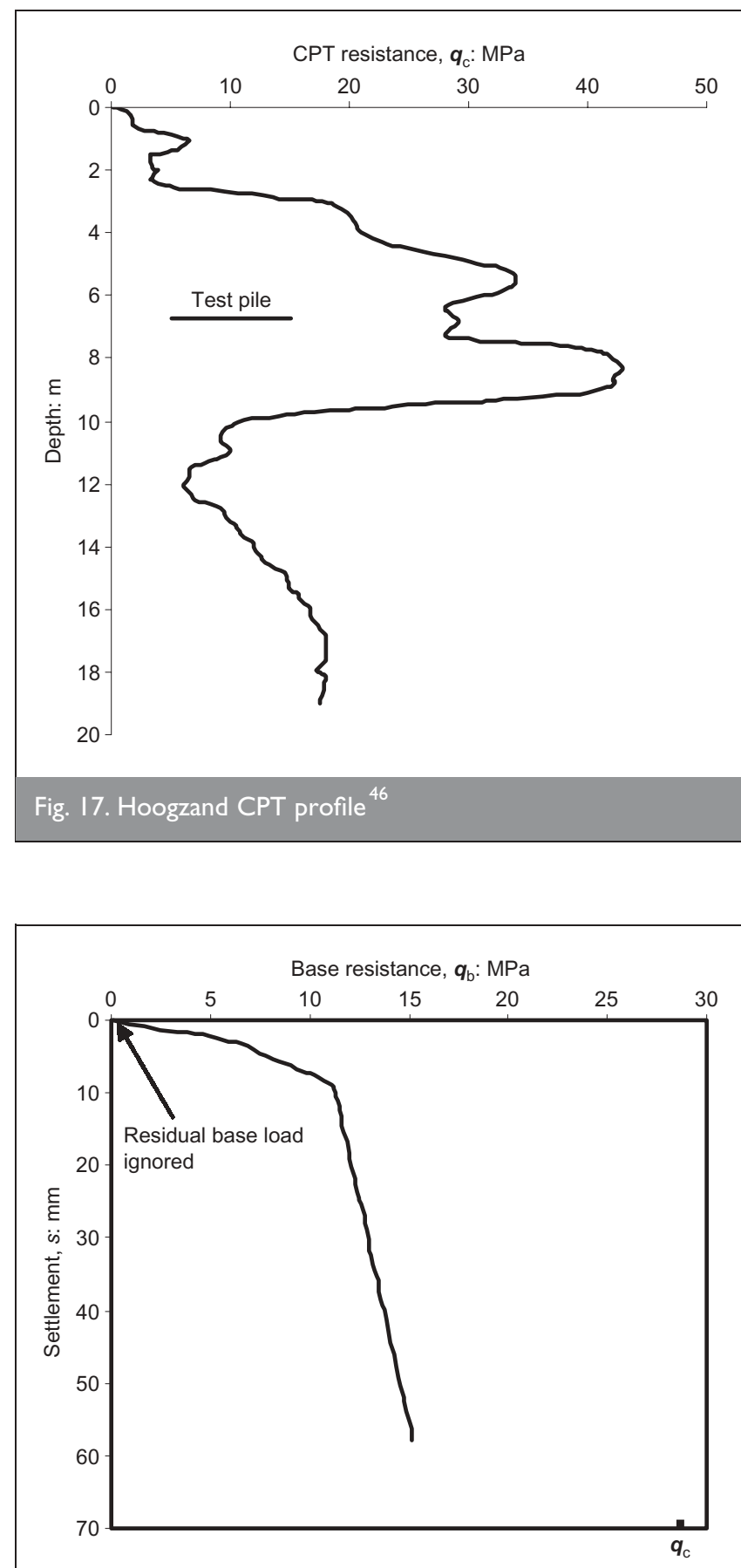

Fig. 18. Hoogzand base load-settlement response ${ }^{46}$

interpreted as described in this paper. Instead, $\boldsymbol{q}_{\mathrm{b}}$ is typically slightly lower than $\boldsymbol{q}_{\mathrm{c}}$, but no trend with diameter is evident.

The outlying points on Fig. 2, for which $\boldsymbol{q}_{\mathrm{b}} / \boldsymbol{q}_{\mathrm{c}}<0 \cdot 5$, comprise data from sites for which $\boldsymbol{q}_{\mathrm{c}}$ has been estimated from SPT data, with the exception of the data point for Drammen, for which residual loads are not fully accounted for. The selection of alternative empirical SPT-CPT correlations can alter the position of these points by a factor of 2 in either direction. A more stringent acceptance criterion for pile tests to be included in this database would be to exclude sites for which actual CPT data are not available.

When considering only the load tests for which a 'plunging' capacity can be identified, the only data point for which $\boldsymbol{q}_{\mathrm{b}} / \boldsymbol{q}_{\mathrm{c}}$

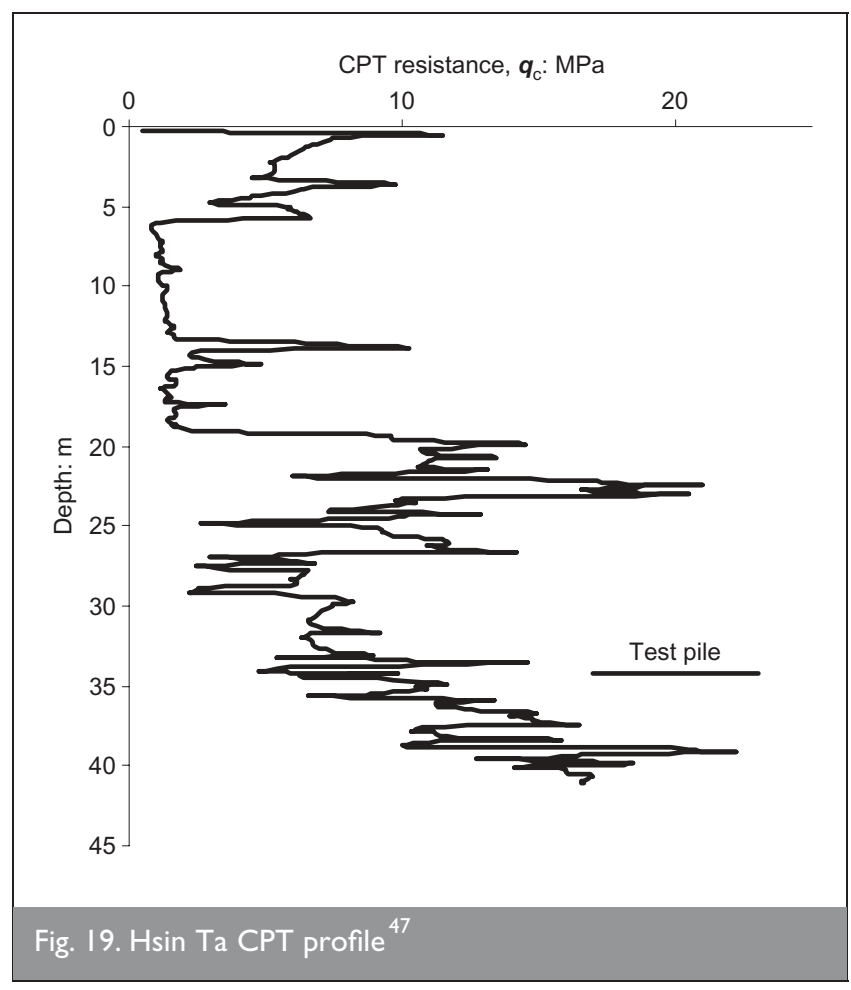

$<0.6$ is from Hsin Ta. However, this test pile was located in a clay layer that is not captured in the CPT profile. If this result is ignored, a mean value of $\boldsymbol{q}_{\mathrm{b}} / \boldsymbol{q}_{\mathrm{c}}=0.90$ is found from the data set of 20 piles. If this relationship is used as a basis for the prediction of $\boldsymbol{q}_{\mathrm{b}}$ at plunging failure, a mean ratio of predicted to measured capacity of 1.02 is found, with a standard deviation of $0 \cdot 17$ and a coefficient of variation of $0 \cdot 17$.

This exercise demonstrates that databases of pile load test data should be treated with caution, and care should be taken to establish the methods used to extract the underlying load test data and ground conditions. However, the differences between Figs 2, 3 and 4 are not random, and cannot be attributed entirely to ambiguous historical field records. The majority of field records of low $\boldsymbol{q}_{\mathrm{b}} / \boldsymbol{q}_{\mathrm{c}}$ that form the basis of the apparent scale effect on diameter evident in Fig. 2 can be attributed to other factors, namely:
(a) partial embedment
(b) residual stresses
(c) partial mobilisation.

\section{I. Partial embedment}

The load tests conducted at Kallo, Lower Arrow Lake and Akasaka comprise piles that are shallowly embedded in dense sand. At this shallow embedment the 'full' capacity of the dense stratum is not mobilised, and the pile tip 'feels' the overlying weak soil. Laboratory tests have shown that this effect can extend to an embedment of several pile diameters, and can be accounted for using a correction of the form of equation (1), illustrated in Fig. 1.

Partial embedment is probably responsible for many further examples of recorded low values of $\boldsymbol{q}_{\mathrm{b}} / \boldsymbol{q}_{\mathrm{c}}$ during pile load tests beyond the data assembled in this paper. Piles bearing in dense sand are usually installed only to a shallow embedment to prevent pile tip damage and driveability problems. 
Noting that several diameters of penetration are required to fully mobilise the strength of the hard layer, engineers are correct to design with $\boldsymbol{q}_{\mathrm{b}} / \boldsymbol{q}_{\mathrm{c} \text {,local }}<1$ in these cases, and will observe the same in load tests. However, this should not be mistaken for a scale effect on absolute diameter, but relates to partial embedment. Installing the pile deeper into the bearing stratum would yield increased $\boldsymbol{q}_{\mathrm{b}} / \boldsymbol{q}_{\mathrm{c}, \text { local }}$ and higher capacity.

\subsection{Residual stresses}

The load test data from Seattle, Hoogzand, Drammen and Baghdad are influenced by residual stresses, in that the measurement of base resistance began from a zero value at the start of the load test (i.e. zero head load), even though some base resistance would have remained locked in by negative shaft friction.

(a) The Baghdad data were corrected for residual base load by the original authors, and show values of $\boldsymbol{q}_{\mathrm{b}} / \boldsymbol{q}_{\mathrm{c}}$ close to unity.

(b) The Drammen data have been corrected in this paper using a simple method yielding values of $\boldsymbol{q}_{\mathrm{b}} / \boldsymbol{q}_{\mathrm{c}}$ between 0.7 and 1 compared with an uncorrected value of $0 \cdot 4$.

(c) Chow ${ }^{13}$ notes that the Hoogzand data show slight evidence of residual stress errors. Although the original authors discuss zero drift and residual stresses, as the base load is recorded as zero at the start of the load test, any residual base load has been ignored. Plunging failure was not reached during this test.

(d) The Seattle data are corrected for residual base load by the original authors using measurements from a nearby identical pile. However, the recorded base load of $12 \%$ of the shaft friction appears low, casting doubt upon their degree of correction.

\subsection{Partial mobilisation}

Plunging capacity was reached prior to a settlement of $D / 10$ for $60 \%$ of the piles. The piles at Baghdad, Drammen, Hunter's Point and Akasaka showed differences between $D / 10$ and plunging capacity. For a $D / 10$ failure criterion, these sites show a mean $\boldsymbol{q}_{\mathrm{b}} / \boldsymbol{q}_{\mathrm{c}}$ of $0 \cdot 75$, which rises to 0.89 for a plunging failure criterion. When assessing pile capacity according to the $D / 10$ displacement failure criterion, the value is influenced by pile stiffness for this subset of $40 \%$ of the piles, with the chosen figure depending on the degree of partial mobilisation. For the remaining $60 \%$ of the database, the pile stiffness is sufficiently high for the choice of failure criterion to have no influence on the inferred capacity.

In this paper, these three mechanisms have been accounted for by:

(a) calculating appropriate values of $\boldsymbol{q}_{\mathrm{b}} / \boldsymbol{q}_{\mathrm{c}}$ when the pile tip is at a shallow embedment in a bearing stratum by using equation (1) to include the weakening contribution of the overlying layer when selecting $\boldsymbol{q}_{\mathrm{c}}$ (Kallo and Lower Arrow Lake sites)

(b) accounting for residual base load by using tension tests to estimate the compressive shaft capacity (Drammen site)

(c) assessing pile capacity based on plunging load. Although this value is often not reached during load tests, and requires a larger safety factor in design, it is a definition that prevents pile stiffness from clouding the measurement of ultimate pile strength, as is the case with a settlement criterion. It should be noted that throughout this paper, where plunging load has not been reached, the maximum load achieved during the load test has been quoted instead. This approach is conservative, and avoids the uncertainty associated with extrapolation methods, which can be unconservative.

Following this methodology, it has been found from the database of field load tests assembled by Chow ${ }^{13}$ that no scale effect on $\boldsymbol{q}_{\mathrm{b}} / \boldsymbol{q}_{\mathrm{c}}$ with absolute pile diameter is evident. Instead, plunging base resistance for this set of pile load test results is best estimated as $90 \%$ of $\boldsymbol{q}_{\mathrm{c}}$ (corrected for partial embedment), and is independent of diameter.

This conclusion indicates that the ratio $q_{\mathrm{b}} / \boldsymbol{q}_{\mathrm{c}}$ is influenced by two of the mechanisms described in the introduction to this paper: partial embedment and partial mobilisation. An appropriate value of $\boldsymbol{q}_{\mathrm{c}}$ at the pile tip to account for partial embedment can be selected by suitable consideration of the low values of $\boldsymbol{q}_{\mathrm{c}}$ in the overlying weak layer. It should be noted that the strength differential between soft and hard layers is typically high, making the corrected value of $\boldsymbol{q}_{\mathrm{c}}$ very sensitive to the weighting technique.

Partial mobilisation can be accounted for by defining $q_{\mathrm{b}}$ as the plunging capacity, and selecting design safety factors (or more correctly mobilisation factors) appropriately. It should be noted that higher safety factors should be applied to plunging loads than to capacities defined by a settlement criterion, although for this database the majority of piles reached plunging load prior to a settlement of $D / 10$. If a safety factor is being used to limit settlement then consideration should be given to pile stiffness, and the factor should be selected appropriately.

After removing these two effects, $\boldsymbol{q}_{\mathrm{b}}$ is on average 10\% lower than $\boldsymbol{q}_{\mathrm{c}}$. This effect could be attributed to local inhomogeneity, base-shaft interaction, or more probably to the conservative definition of plunging capacity as the maximum applied load in the load tests for which steady penetration under constant load was not reached.

\section{CONCLUSIONS}

The comprehensive database of load tests on closed-ended piles in sand presented by Chow ${ }^{13}$ has been reassembled from the original sources to examine the relationship between CPT resistance, $\boldsymbol{q}_{\mathrm{c}}$, and base capacity, $\boldsymbol{q}_{\mathrm{b}}$. In contrast to continuum analyses that predict $\boldsymbol{q}_{\mathrm{b}}=\boldsymbol{q}_{\mathrm{c}}$ during steady penetration, reduction factors are often recommended such that $\boldsymbol{q}_{\mathrm{b}} / \boldsymbol{q}_{\mathrm{c}}<1$ for design.

Two mechanisms to explain these reduction factors are partial embedment of the pile into the bearing stratum and partial mobilisation of base resistance. In this analysis, partial embedment has been accounted for by weighting $q_{\mathrm{c}}$ to account for overlying weak layers in the case of piles shallowly embedded into a bearing stratum. Partial mobilisation has been accounted for by defining failure according to a plunging criterion.

The resulting values of $\boldsymbol{q}_{\mathrm{b}} / \boldsymbol{q}_{\mathrm{c}}$ have a mean value of 0.90 and show no trend with pile diameter, for the 20 load tests in which 


\begin{tabular}{|c|c|c|}
\hline Site & CPT profile, $q_{\mathrm{c}}$ & Base load-settlement curves, $q_{b}-s$ \\
\hline Dunkirk ${ }_{33}^{13}$ & Fig. 5 & Fig. 6 \\
\hline Labenne $^{33}$ & Fig. 7 & Fig. 8 \\
\hline Kallo $^{34}$ & Fig. 9 & Fig. 10 \\
\hline Hunter's Point ${ }^{35}$ & Fig. II & Fig. 12 \\
\hline Baghdad 36,37 & Fig. 13 & Not given in original reference \\
\hline Akasaka $^{39}$ & Fig. 14 & Fig. 15 \\
\hline Drammen ${ }^{40}$ & Fig. 16 & $\begin{array}{l}\text { Failure load corrected for residual load in this } \\
\text { paper. Original uncorrected data not shown }\end{array}$ \\
\hline Arkansas $^{43}$ & SPT & $\begin{array}{l}\text { Original data uncorrected for residual load } \\
\text { not shown }\end{array}$ \\
\hline Hoogzand ${ }^{46}$ & Fig. 17 & Fig. 18 \\
\hline $\mathrm{H} \sin \mathrm{Ta}^{47}$ & Fig. 19 & Not given in original reference \\
\hline Seattle ${ }^{48}$ & SPT & Not given in original reference \\
\hline Lower Arrow Lake ${ }^{51}$ & SPT & $\begin{array}{l}\text { Base capacity estimated in original reference } \\
\text { by comparing open and closed-ended tests }\end{array}$ \\
\hline
\end{tabular}

plunging load was identified and reliable values of $\boldsymbol{q}_{\mathrm{c}}$ were available. That only 20 high-quality load tests are available for this study reflects the poor basis upon which design approaches for piles in sand can be verified, and this outcome should be seen as a contribution pending further test data rather than a recommendation. Further research and the publication of proprietary load test data would be valuable.

The slight underprediction of the 'continuum' model $\left(\boldsymbol{q}_{\mathrm{b}}=\boldsymbol{q}_{\mathrm{c}}\right)$ could be attributed to the underestimation of plunging load in pile tests for which steady penetration was not reached. This exercise brings into question the use of a diameter-based reduction factor on $\boldsymbol{q}_{\mathrm{c}}$ for the ultimate end bearing capacity of closed-ended piles in sand. Instead, it is suggested that reduction factors should be linked to partial embedment and partial mobilisation.

\section{APPENDIX: CONE PENETRATION DATA AND LOAD TEST RESULTS}

Where available in the original reference, the cone penetration data and base load-settlement results from each site are reproduced in Table 6 . The 'design' cone resistance, $\boldsymbol{q}_{\mathrm{c}}$, taken as a local average $( \pm 1 \cdot 5 D)$, or using equation (1) for partial embedment as described previously, is indicated on each loadsettlement curve.

\section{REFERENCES}

1. KAY J. N. Ultimate capacity of driven piles in sand. Proceedings of the Institution of Civil EngineersGeotechnical Engineering, 1997, 125, No. 2, 5-70.

2. LINGS M. L. Predicting the shaft resistance of driven preformed piles in sand. Proceedings of the Institution of Civil Engineers-Geotechnical Engineering, 1997, 125, No. 2, 71-84.

3. RANDolph M. F., Dolwin J. and BeCK R. Design of driven piles in sand. Géotechnique, 1994, 44, No. 3, 427-448.

4. JARDine R. J. and Chow F. C. New Design Methods for Offshore Piles. Marine Technology Directorate, London, 1996, MTD Publication 96/103.

5. BALIGH M. M. Strain path method. ASCE Journal of Geotechnical Engineering, 1985, 111, No. 9, 1108-1136.

6. Bustamante M. and Gianeselli L. Pile bearing capacity by means of static penetrometer CPT. Proceedings of the 2nd European Symposium on Penetration Testing, Amsterdam, 1982, 493-500.

7. De Rutter J. and Beringen F. L. Pile foundations for large North Sea structures. Marine Geotechnology, 1979, 3, No. 3, 267-314.

8. MeYerhoF G. G. Bearing capacity and settlement of pile foundations. ASCE Journal of Geotechnical Engineering, 1976, 102, No. GT3, 197-228.

9. Meyerhof G. G. and Valsangkar A. J. Bearing capacity of piles in layered soils. Proceedings of the 8th International Conference on Soil Mechanics and Foundation Engineering, Moscow, 1977, 1, 645-650.

10. WinterKoRn A. F. and FANG S. Y. Foundation Engineering Handbook. Van Nostrand Reinhold, New York, 1975.

11. Borghi X., White D. J., Bolton M. D. and Springman S. Empirical pile design based on CPT results: an explanation for the reduction of unit base resistance between CPTs and piles. Proceedings of the 5th International Conference on Deep Foundation Practice, Singapore, 2001, 125-132.

12. KRAFT L. M. Computing axial pile capacity in sands for offshore conditions. Marine Geotechnology, 1990, 9, 61-72.

13. CHow F.C. Investigations into the Behaviour of Displacement Piles for Offshore Foundations. PhD thesis, University of London (Imperial College), 1997.

14. MeYerhof G. G. Scale effects of ultimate capacity. ASCE Journal of Geotechnical Engineering, 1983, 109, No. 6, 797-806.

15. Tejchman A. and Gwizdala K. Analysis of safety factors of bearing capacity for large diameter piles. Proceedings of the 7th European Conference on Soil Mechanics and Foundation Engineering, Brighton, 1979, 1, 293-296.

16. DE BEER E. E. Bearing capacity of shallow foundations on sand. Proceedings of a Symposium on Bearing Capacity and Settlement of Foundations, Duke University, 1965, pp. 15-33.

17. GotTARdi G., Ricceri G. and Simonini P. On the scale effect of footings on sand under general loads. Proceedings of the 13th International Conference on Soil Mechanics and Foundation Engineering, New Delhi, 1994, 709-712.

18. Clark J. I. Settlement and bearing capacity of very large 
foundations on strong soils. Canadian Geotechnical Journal, 1998, 35, No. 1, 131-145.

19. Bolton M. D. The strength and dilatancy of sands. Géotechnique, 1986, 36, No. 1, 65-78.

20. Graham J. and Hovan J. M. Stress characteristics for bearing capacity in sand using a critical state model. Canadian Geotechnical Journal, 1986, 23, No. 2, 195-202.

21. Ueno K., Miura K., Kusakabe 0. and Nishimura M. Reappraisal of size effect of bearing capacity from plastic solution. ASCE Journal of Geotechnical and Geoenvironmental Engineering, 2001, 127, No. 3, 275-281.

22. ZHU F., CLARK J. I. and PHILLIPS R. Scale effect of strip and circular footings resting on dense sand. ASCE Journal of Geotechnical and Geoenvironmental Engineering, 2001, 127, No. 7, 613-621.

23. GARNIER, J. Size effect in shear interfaces. Proceedings of a Workshop on Constitutive and Centrifuge Modelling: Two Extremes, Monte Verita, 2002, pp. 335-346.

24. Petley D. J. The Shear Strength of Soils at Large Strains. $\mathrm{PhD}$ thesis, University of London, 1966.

25. CUCKSON J. Shear Zones and Progressive Failure in Overconsolidated Clay. PhD thesis, Cambridge University, 1977.

26. Palmer A. C., White D. J., Baumgard A. J., Bolton M. D., Barefoot A. J., Finch M., Powell T., Faranski A. S. and BALDRY J. A. S. Uplift resistance of buried submarine pipelines: comparison between centrifuge modelling and full-scale tests. Géotechnique, 2003, 53, No. 10, 877-883.

27. MeYerhof G. G. The ultimate bearing capacity of foundations. Géotechnique, 1951, 2, No. 4, 301-332.

28. BerezantzeV V. C., Kristoforov V. and GolubKoV V. Loadbearing capacity and deformation of piled foundations. Proceedings of the 4th International Conference on Soil Mechanics and Foundation Engineering, Paris, 1961, 2, $11-12$.

29. WhITE D. J. An Investigation into the Behaviour of Pressedin Piles. PhD thesis, Cambridge University, 2002.

30. White D. J. and Bolton M. D. Displacement and strain paths during pile installation in sand. Géotechnique, 2004 54, No. 6, 375-397.

31. LeE J. H. and SAlgado R. Determination of pile base resistance in sands. ASCE Journal of Geotechnical and Geoenvironmental Engineering, 125, No. 8, 673-683.

32. WHITE D. J. Field Measurements of CPT and Pile Base Resistance in Sand. Cambridge University Engineering Department, 2003, Technical Report CUED-D-SOILS-TR327.

33. LEHANE B. M. Experimental Investigations of Pile Behaviour Using Instrumented Field Piles. PhD thesis, Imperial College, University of London, 1992.

34. De Beer E. E., Lousberg D., De Jonghe A., Carpentier R. and WALLAYS M. Analysis of the results of loading tests performed on displacement piles of different types and sizes penetrating at a relatively small depth into a very dense layer. Proceedings of a Conference on Recent Developments in the Design and Construction of Piles, London, 1979, pp. 199-211.

35. Briaud J.-L., TucKer L. M. and Ng E. Axially loaded 5 pile group and a single pile in sand. Proceedings of the 12th International Conference on Soil Mechanics and Foundations Engineering, Rio de Janeiro, 1989, 2, 1121-1124.

36. Altaee A., Fellenius B. H. and Evgin E. Axial load transfer for piles in sand. I. Tests on an instrumented precast pile. Canadian Geotechnical Journal, 1992, 29, No. 1, 11-20.

37. Altaee A., Fellenius B. H. and Evgin E. Load transfer for piles in sand and the critical depth. Canadian Geotechnical Journal, 1993, 30, No. 3, 455-463.

38. FelleniUS B. H. Prediction of pile capacity. Proceedings of a Symposium on Predicted and Observed Behaviour of Piles, ASCE Special Geotechnical Publication 23, 1989, pp. 293-302.

39. ВСР COMMITTEE. Field tests on piles in sand. Soils and Foundations, 1971, 11, No. 2, 29-49.

40. Gregersen 0. S., AAS G. and Dibiagio E. Load tests on friction piles in loose sand. Proceedings of the 8th International Conference on Soil Mechanics and Foundation Engineering, Moscow, 1973, 2, 109-117.

41. De Nicola A. and RAndolPh M. F. Tensile and compressive shaft capacity of piles in sand. ASCE Journal of Geotechnical Engineering, 1993, 119, No. 12, 1952-1973.

42. LehANE B. M., JARdine R. J., Bond A. J. and FRANK R. Mechanisms of shaft friction in sand from instrumented pile tests. ASCE Journal of Geotechnical Engineering, 1993, 119, No. GT1, 19-35.

43. MANSUR C. I. and HunTER A. H. Pile tests: Arkansas River project. Journal of the Soil Mechanics and Foundations Division, ASCE, 1970, 96, No. SM5, 1545-1582.

44. Coyle H. M. and CAstello R. R. New design correlations for piles in sand. ASCE Journal of Geotechnical Engineering, 1981, 197, No. GT7, 965-985.

45. LUNNE T. and ChristofFerson H. P. Interpretation of cone penetrometer data for offshore sands. Proceedings of the Offshore Technology Conference, OTC4464, Houston, 1983, 181- 192.

46. BERINGEn F. L., WindLe D. and VAN HoOYDONK W. R. Results of loading tests on driven piles in sand. Proceedings of a Conference on Recent Developments in the Design and Construction of Piles, London, 1979, pp. 213-225.

47. Yen T. L, Lin H., Chin C.-T. and WANG R.-F. Interpretation of instrumented driven steel pipe piles. Proceedings of a Congress on Foundation Engineering: Current Principles and Practice, Illinois, 1989, pp. 1293-1308.

48. GURTOWSKI T. M. and Wu M.-J. Compression load tests on concrete piles in alluvium. Proceedings of a Symposium on the Analysis and Design of Pile Foundations, San Francisco, 1984, pp. 138-153.

49. Burland J. B. and BuRBidge M. C. Settlement of foundations on sand and gravel. Proceedings of the Institution of Civil Engineers, 1985, 78, No. 1, 1325-1381.

50. MeIGH A. C. Cone penetration testing: methods and interpretation. CIRA Ground Engineering Report, 1987, 141 pp.

51. McCAmmon N. R. and Golder H. Q. Some loading tests on long pipe piles. Géotechnique, 1970, 20, No. 2, 171-184.

Please email, fax or post your discussion contributions to the secretary by I July 2005: email: mary.henderson@ice.org.uk; fax: +44 (0)20 665 2294; or post to Mary Henderson, Journals Department, Institution of Civil Engineers, I-7 Great George Street, London SWIP 3AA. 